\title{
The laws of mutual adaptation and transformations applied to language origin and fostering artificial talent
}

\author{
Valeri F. VENDA ${ }^{1}$, Sergei S. Kostenko ${ }^{2}$ \\ ${ }^{1} \mathrm{DSc}$ (psychology), $\mathrm{PhD}$ (engineering), honorary fellow Human factors and ergonomics \\ society (HFES), USA (since 2002), recipient international awards for outstanding research in \\ psychology (USSR Academy of science, 1984) and in human factors and ergonomics society \\ (USA, HFES, 1996). Ukraine
}

${ }^{2}$ Student of the Kyiv National University of Trade and Economics, Ukraine

Keywords: laws of mutual adaptation and transformation, language origin, supergeniuses, subconscious creative thinking, artificial talent.

\begin{abstract}
V. Venda discovered four laws of mutual adaptation and transformations (Voprosy Phylosofii, \#2, 2017). Previously the laws were tested and practically used in development of new, the transformation learning theory, in prediction of social and economic transitions, in studies of human-computer interaction, design of safe workstations, information gadgets and technological control systems, in development of new science much later named as usability. Here the laws and based on them theory of adaptation are being applied to phylogenesis of human intellect, language origin and evolution of human-environment mutual adaptation.
\end{abstract}


In 2014, N. Chomsky and other leading scientists concluded that modern science could not learn how language was originated. To study this mystery we applied our new laws. We needed to compare modern intellect with intellect those who were able to originate language. We concluded those were people with complete neocortex, the "supergeniuses". "Supergeniuses" instead of the passive role of an evolutionary animal mainly adapting to the environment, subjugated to themselves the processes of mutual adaptation with the environment, minimizing man's own evolution and thus his risky structural transformations.

Language as the most powerful means of mutual adaptation between people made it possible to better train, mutually adapt and organize large groups of warriors, hunters, and gatherers and thus successfully survive. Mutual adaptation proved to be a main system-developing factor in any system. In tribe, it worked especially well when language was originated. Language not only helped better mutually adapt members of tribe but it also helped to mutually disadapt members of the tribe with their enemies and easily find spies who were unable to use the tribe language as their native one.

However, the language helped well if it was alone within the tribe. The supergeniuses who continued creating the new languages had to be expelled from the tribes. Supergeniuses created about 7,000 languages. Peoples brought their languages and settled across the Earth as its masters.

With the beginning of the persecution of supergeniuses for creating new languages, they got stress and began to lose up to $70 \%$ of neocortex neurons before birth. That decreased their intellectual abilities. Possibly the most tragic coincidence occurred in evolution. Homo sapiens became masters of the planet and at the same time, they lost ability to predict remote consequences of their influence on environment and on their own life.

However, the remaining neurons are enough for children to be geniuses in the creative mastery of language and intuitively studying the laws of nature, including the laws of mutual adaptation. Using more productively sleep time an ordinary child may be brought up as a creative talent. The author confirmed this in experiment 70 years long.

\section{Intellectual creativity of our ancestors and modern humans}

Our hypothesis is to justify that, in contrast to the generally accepted views, the ancient people who created for us universal grammar and language - these are the greatest intellectual creative achievements of all time [Deutscher 2005, Klein 2009, Tattersall 2012], surpassed us, 
modern Homo sapiens, in intelligence and creativity. There is doubt about the truth of the ideas of modern philosophy and psychology expressed for example by K.G. Jung. He described the contemporary as a person standing on the top or on the very edge of the world with the abyss of the future in front of him, the heavens above him and all of humanity history disappearing in the primeval fog - beneath him. We will try to dismiss this presentation of a modern human as a semi-god. If my hypothesis is proved, then many fundamental principles of philosophy, psychology and a number of other humanitarian sciences have to be revised.

What led me to put forward such a sacramental hypothesis? Firstly, one event, which is extraordinary for philosophy and psychology, requires revising the evolution of human intelligence. In 2014, the founder of modern linguistics N. Chomsky and his authoritative colleagues recognized that neither they nor anyone else could find out how the language was created, including its universal grammar [Hauser, Yang, Berwick, Tattersall, Ryan, Watumull, Chomsky, Lewontin 2014].

Thus, our contemporaries admitted defeat in intellectual competition with ancient ancestors. To justify and explain the defeat we have to assume that those ancestors were supergeniuses able to create grammars and languages.

Recall that the surrender of modern scientists was not hasty. Attempts to solve the problem of the origin of the language began a long time ago, at least more than one and a half centuries ago. In 1866, the Paris Linguistic Society announced that it would no longer accept applications and articles on this topic, since they were all helpless to find out language origin. However, very intensive studies of the origin of the language continued until 2014.

The results of this mass experiment lasting one and a half centuries allowed me to put forward the hypothesis formulated above about the intellectual creative superiority of Homo sapiens, who lived in the era of the creation of the language, before us, modern people.

Following K. Marx, who proposed in his "Capital" to use time as a universal criterion of complexity of work I developed a theory of complexity of intellectual activity [Venda 1975, 1990, Venda, Venda 1995]. I considered time spent on problem solving as the most important criterion for measurement of the intellectual complexity of a problem.

Secondly, the formulation and justification of my hypothesis was influenced by my discovery of the laws of mutual adaptation and transformations of systems (Venda 1988, Venda, Venda 1991, Venda 1993, 2017). 
The failure of linguists in 2014 on language origin and other events in the scientific world served as an impetus for the intensive application of my laws of mutual adaptation and transformations to studies of phylogenesis and ontogenesis of human intelligence and creativity.

I am personally responsible for these laws, that is why I gave them the names of the First, Second, Third and Fourth Venda laws. The history of the discovery of these laws, their origin from the general theory of systems and their role of the general laws of nature are discussed in detail in a number of books and articles [Venda 1990, 2017, Venda, Venda 1991, 1995]. Here is their final wordings.

\section{The laws of mutual adaptation and transformations}

The First law of Venda or the law of mutual adaptation:

The development and existence of any system includes the processes of mutual multilevel adaptation of system inner components among themselves and of the system as a whole with its external environment including other systems.

Examples of this law include the observation of biological cell, anatomy and physiology of a person or of any animal, relations between spouses, the political map of the world, and map of the solar system.

For example, weakening of mutual adaptation of citizens within Ukraine in 2014 led to the fact that Crimea left it and joined Russia. In addition, two unrecognized republics were formed in the Donbas, the mutual adaptation of which with the rest of Ukraine temporarily decreased.

The First law of Venda points to the process of mutual multi-level adaptation as a universal system-forming factor, mandatory for the formation, development and life of any system. If mutual multi-level adaptation in a human is analyzed, then we found the following levels: cellular, biological, morphological, physiological, psychophysiological, psychological and sociological. For example, in training astronauts we observed mutual adaptation processes at all these levels including cellular one [Venda, 1975, 1990] 
The Second law of Venda or the law of maximum efficiency: The efficiency of the system with its structure unchanged is maximum if the value of the controlled factor of mutual adaptation is optimal.

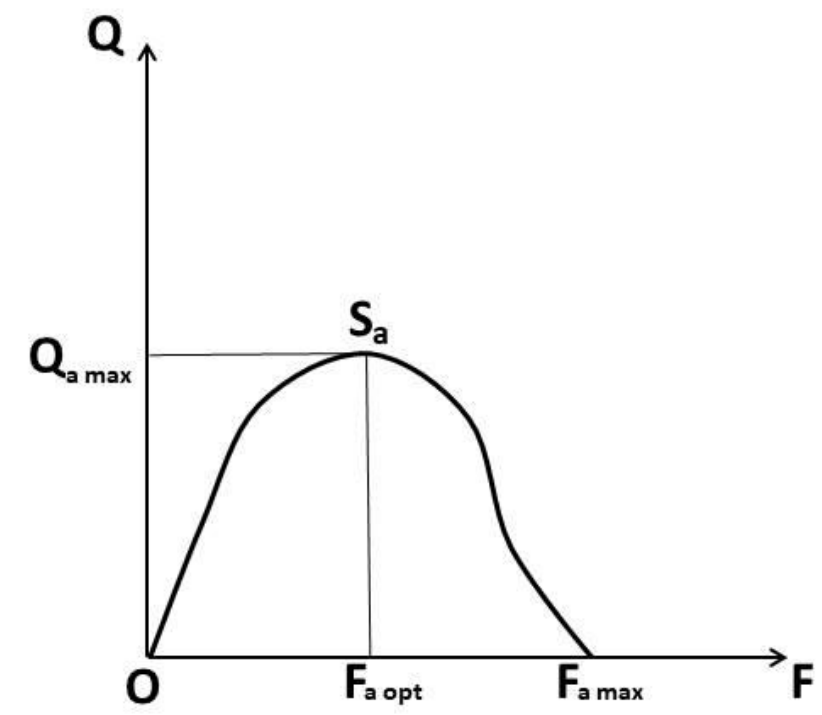

Fig. 1. Visualization of the Venda Law \#2. System with structure Sa has a maximal efficiency Qamax if mutual adaptation factor $F$ has optimal value Faopt.

Graphically, this law is illustrated in Figure 1 in the form of a bell-shaped curve of the dependence of efficiency Q (ordinate) on the factor of mutual adaptation F (abscissa). In the particular case, this curve can be a parabola. However, it is important that the curve has one optimum; otherwise, we are dealing with two or more structures. Any indicator whose maximization is useful to the system, for example, the probability of survival of a biological species or ecosystem, can serve as a performance efficiency criterion (Q). An opposite criterion calculated as $1-\mathrm{Q}$ or $1 / \mathrm{Q}$ is a criterion of the task solving complexity. The law indicates that the dependence of Q on the factor of mutual adaptation is always a curve with a single optimum, e.g. with a "hump". This dependence is never expressed in a straight line. 
With the discovery of this law, we theoretically refuted the Weber-Fechner law. This was confirmed by extensive experimental data [Masin 2009].

The Third law of Venda, or the law of plurality of structures:

The system can have a number of structures, each of which corresponds to a special bell-shaped curve of the dependence of system efficiency on the factor of mutual adaptation of the system with the environment.

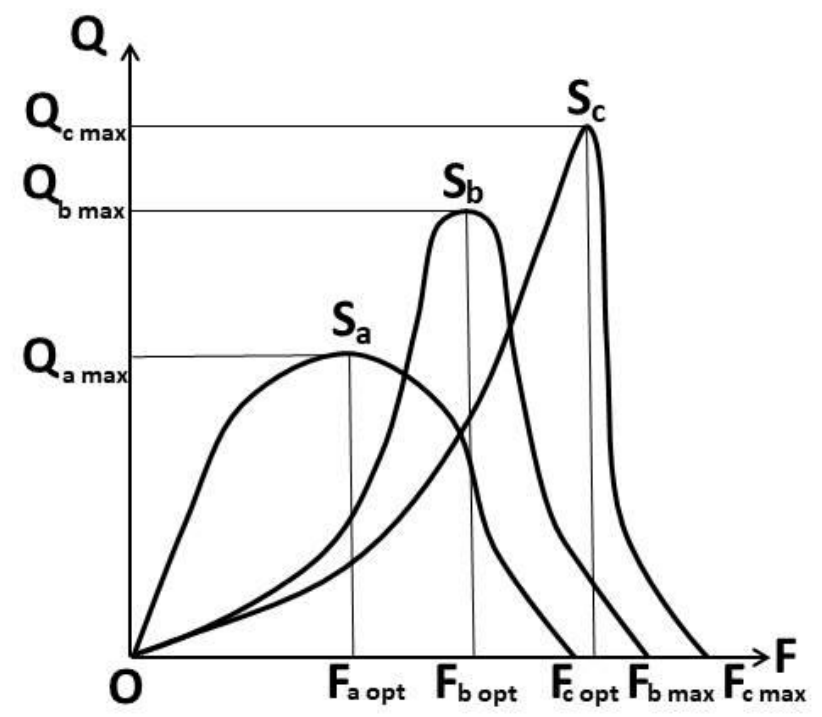

Fig. 2. Visualization of the Venda Law \#3. System may have a number of strucrures Sa, Sb, Sc with maximal efficiencies of Qamax, Qbmax, Qcmax when factor of mutual adaptation has values Faopt, Fbopt, Fcopt.

Figure 2 shows as example three bell-shaped curves describing the dependence of the efficiency $\mathrm{Q}$ of the system $\mathrm{S}$ on one factor of mutual adaptation $\mathrm{F}$ for three different structures of the system $\mathrm{Sa}, \mathrm{Sb}$ and $\mathrm{Sc}$.

In accordance to the Third law of Venda, a grammar might have several structures, even though only one survived and exists now as the universal one.

The Fourth law of Venda or the law of transformations of system structures: 
The structures of the system are transformed one into another with a minimum loss of efficiency through a common state of the system for previous and for the next structures.

The state of the system, common to the two structures, is represented as the intersection point of their bell-shaped curves (Figure 3).

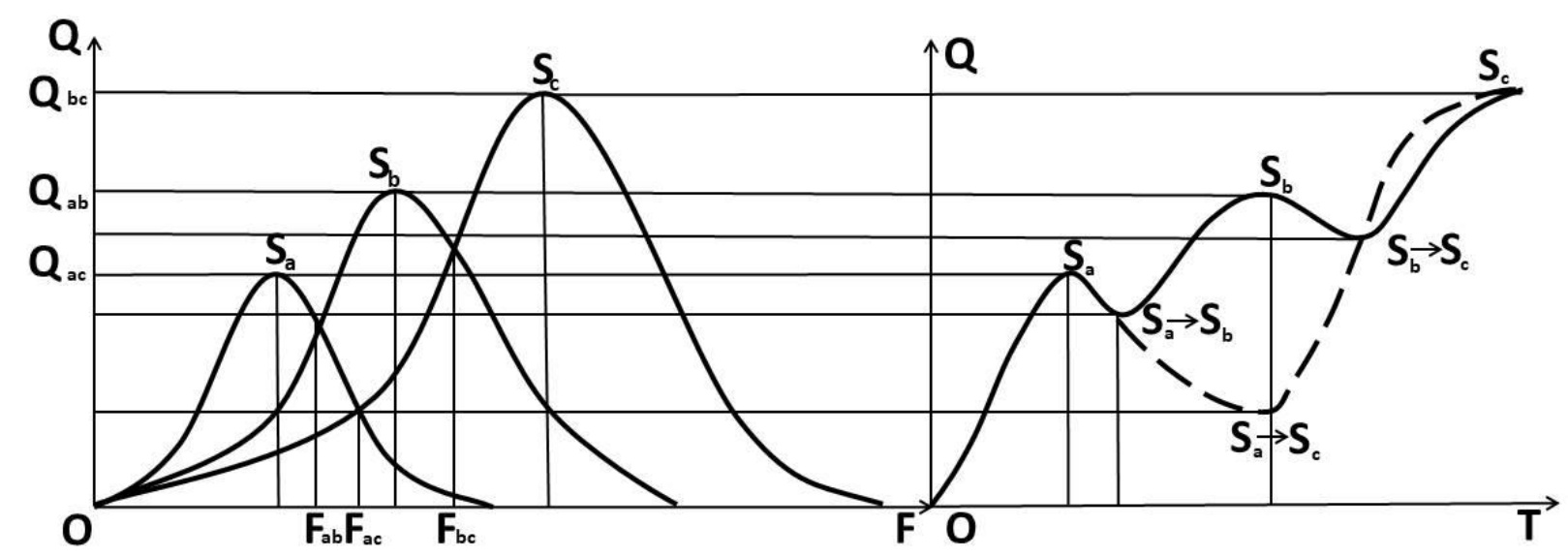

Fig. 3. Visualization of the Venda Law \#4. Transformations between system structures Sa, Sb, Sc go through the common points with mutual adaptation factor values Fab, Fbc, Fac.

There is a difference between the optimal values of the mutual adaptation factor for two different structures. The two structures are displayed by different bell-shaped curves. Consequently, the intersection of these curves occurs in the saddle, that is, when the efficiency is lower than the maximum efficiency values for each of these two structures. Therefore, the efficiency of the common state of the system for these structures is lower than the maxima for each structure.

The Fourth law of Venda explains why, when a system is transforming its structure the effectiveness of the system at least temporarily decreases.

For example, the survival of a species during its evolution is reduced. Probability of illness and death of a person is higher during transformations of the organism, including transformations between different structures in aging of person [Venda, 1990]. 
The fourth law of Venda is illustrated in Fig. 3. The bell-shaped curves of the three structures $\mathrm{Sa}, \mathrm{Sb}$ and $\mathrm{Sc}$ are shown on the left. Each structure has its optimal value of the mutual adaptation factor Faopt, Fbopt and Fcopt. The factor F values common to the two structures, through which the most economical, from the point of view of falling efficiency criterion $\mathrm{Q}$, transformation of one structure into another, Fab, Fac, Fbc . Left part of Fig. 3 shows the static dependences of the performance criterion Q on factor F. Right part of Figure 3 shows the dynamics of the system $\mathrm{S}$ with three possible structures $\mathrm{Sa}, \mathrm{Sb}, \mathrm{Sc}$ over time T. Figure 3 shows that the transformation between the structures occurs in the saddles between the maxima of two corresponding transforming structures [Venda 1990; Venda, Venda 1991].

At the same time, in accordance with the Fourth law of Venda, any other trajectory of transformation of one structure into another will lead to an even greater decrease in the efficiency of the system.

An important consequence of the law of transformations is that even a progressive transformation, from less efficient to more efficient structure, occurs with a temporary decrease in the efficiency of the system.

The Fourth law of Venda served as the basis for our creation of a new, the transformation learning theory [Venda 1986]. The possibilities of this theory in experimental and mathematical studies of learning processes, in particular language learning, and cognition (in the broadest sense) are much wider than, for example, the well-known learning theory published by G. Ebbingaus in 1890 and still considered by some as classical, and other learning theories, including those by R. Atkinson, W. Estes, and R.D. Luce.

Work on our laws led, in particular, to the proof that the well-known "Luce axiom" [Luce, Edwards 1958] is incorrect. Our numerous experiments [Venda 1969; Venda 1975] refuted the "Luce axiom" which R.D. Luce presented as his law [Venda 1986]. We have proved that the practical use of the Luce axiom is extremely dangerous, it can lead to operator overloading with irrelevant information. This increases probability of errors in solving emergency tasks and in technological disasters [Venda, Venda 1995].

For half a century, my laws of mutual adaptation and transformation, which are the universal laws of nature [Venda 2017], even in their preliminary wordings have been successfully applied mainly in the design and optimization of human-machine-environment systems [Venda, Venda 1995] and of human-computer interaction [Hoadley 1997]. Here, these laws 
are applied to the problems of the phylogenesis of human intelligence and language origin, as well as to the experimental analysis of the ontogenesis of creative intelligence.

\section{The laws of mutual adaptation and the evolution process}

Application of our laws allowed studying the process of human evolution as a multi-level mutual adaptation between a person, tools and the environment. The Fourth Law of Venda helps to understand that any transformation of the structure of the system, including biological evolution, at least temporarily, reduces the survivability and effectiveness of the system [Venda 1990, 2017]. This is shown on the right side of Fig. 3. The Fourth Law of Venda shows why living systems if possible resist and try to avoid the evolution of their species. The result of the intensive evolution of the species is difficult to predict, it may suddenly lead to its extinction.

Transformation process may be reversible. Then it goes back through the common state for the structures (Fig. 3). The border conditions for the Laws of Venda including Law \#4 were analyzed in detail [Venda 1990].

When Homo sapiens in the course of their evolution got a neocortex, and with it a huge additional cerebral mental resource, this allowed them to limit their evolution. After that, man got able to actively shift the emphasis of his mutual adaptation with the environment from himself to the tools he invented and the environment he was transforming. For example, to provide himself with a comfortable microenvironment, man invented warm dwellings made of mammoth bones and skins [Klein 2009, Tattersall 2012].

\section{Mutual adaptation and evolution of human intellect}

The appearance of the neocortex, according to various sources between 200,000 [Berwick, Pietroski, Yankama, Chomsky 2011, Chomsky 2004] and 40,000 [Klein 2009] years ago, allowed a person to perform superfast mental operations necessary to create a language, mastery and operate it. It should be noted that not a single supercomputer is now capable of simulating these processes [Berwick; Chomsky 2016, Chomsky 2004, Deutscher 2005].

It is known that some neurons from the neocortex are lost even at the stage of prenatal development of the human fetus [Badsberg-Samuelsen, Bonde-Larsen, Bogdanovic, Laursen, 
Gram, Larsen, Pakkenberg 2003]. It can be assumed that at some stage of his development, Homo sapiens had a complete neocortex, that is, all neocortex neurons were present and potentially active. We call such people supergeniuses, since they have been able to create very capacious, concise and useful languages activating mutual adaptation and communication between people. These basic languages served as grammars [Hauser, Yang, Berwick, Tattersall, Ryan, Watumull, Chomsky, Lewontin 2014] for the further development of a variety of tribal and national languages.

Works by V.A. Lectorskiy in classical and non-classical epistemology [Lectorskiy 2001] led us to the idea that grammars could be different. The plurality of structures of each system is enshrined in the Third Law of Venda.

Based on each grammar, a group of languages could arise, the speakers of which could somehow understand each other and mutually adapt, creating tribal unions. Homo sapiens, members of different tribal unions based on different grammars, could not communicate and understand each other [Chomsky 1973, 1986, 2000, Mithen 2006].

A stronger and more numerous union could fight and destroy people incomprehensible to members of its tribes from weaker unions based on other grammars. We suppose that the natural selection of that grammar, on which all modern languages are based, could have happened this way if it was not the only one created by supergeniuses. The single grammar used now by all languages should have established itself before the exodus of Homo sapiens from Africa.

This grammar became the only one for all future languages. The attempt of supergeniuses to create one more grammar or several other grammars and thus undermine the mutual adaptation between the members of the remaining single union could be punishable by death. Because of this threat, stress arose, and supergeniuses began to lose some of the neurons in the neocortex and finally they lost the ability to create new grammars. However, supergeniuses of top level who lost ability to create grammar even after losing that part of the neurons still could create languages. They ceased to be supergeniuses of grammars; they became supergeniuses of lower level, those of languages. In their neocortex, there were still many more neurons than there is in the neocortex of modern man. 


\section{Mutual adaptation in language origin}

By the exodus of people from Africa, there remained one common grammar, which gave all people the basis for mutual adaptation by understanding through translations between languages [Berwick; Chomsky 2016, Chomsky 2004, Deutscher 2005].

Between people who still lived in Africa and used the same grammar and one language, peace was probably established. However, this peaceful world did not last long. People remained supergeniuses, which even with the neocortex trimmed after the grammar events retained ability to create new languages.

If tribe had not only grammar, but also a developed, rich language the tribe got a huge advantage for mutual adaptation between the members of the tribe in ordinary life, joint work, in hunting and wars. Such a tribe was strong and had a good chance of survival.

However, supergeniuses may have created new languages, which introduced desynchronization into the tribe, interfered with its survival and threatened death with people. Creating a new language, each super genius wanted to become a leader, own all the women of the tribe and spread its genes, which was a natural aspiration from the point of view of evolution. Such supergenius came into conflict with the leaders; they violated the established structure of the tribe, because the mutual adaptation between the members of the tribe diminished.

Supergeniuses - the authors of the new language were too smart and creative to survive in their tribe. They became outcasts; they were expelled from the tribe along with their families and like-minded people speaking the new language.

The persecution of too smart and creative people, often manifested even now, has deep evolutionary roots.

Supergeniuses created everywhere very developed languages. For example, the representative of the small Caucasian people of the Avars R. Gamzatov was internationally recognized as a talented poet. Supergeniuses had a powerful brain organ - a neocortex with a large set of ultrafast neurons. In order to keep their brain alive (according to the first evolutionist J.-B. Lamarck who talked about any organ), active and healthy, supergeniuses had to constantly keep it working. They created new developed, rich languages and brought them wherever they could reach through the land, mountain roads and ocean expanses.

In accordance with our hypothesis, this is why Homo sapiens settled the world and hostile relations around arose between neighboring peoples separated by short distances, sometimes by one mountain pass, but using different languages. 
Authors of new languages in tribes turned out to be superfluous, where there was already one adopted "native" language. Authors of new languages who threatened survival of the tribe could be expelled from the tribe or killed.

As a result, supergeniuses who could create languages have experienced extreme stress. Stress led to mutations, mutations eliminated the source of stress - they destroyed the excessive brain resource of supergeniuses of the tongue, depriving of their ability to create new languages. In order to undergo natural selection and survive, language supergeniuses had to lose some of their creativity, become ordinary people and be satisfied with the use of the language that became native for their fellow tribesmen.

Thanks to the neocortex, the emergence of supergeniuses and the creation of the Homo sapiens language, they are the only humanoid ones managed to survive. Now evolution was supposed to deprive a person of supergenius abilities in order for him to survive. This can be called a reverse evolution.

Therefore, in favor of the future man on Earth, his survival, the dilemma that arose then was resolved. Either human intellectual creativity was lowered to the optimal level, or Homo sapiens' chances of survival were low. The victory was won by people with the optimal level of intelligence by the criterion of survival.

The supergeniuses of the tongue as once the supergeniuses of grammar, were finally supplanted from the species Homo sapiens, they completely died out.

The intellectual creativity level of people has decreased, so that they have lost the ability to create new languages. Moreover, people no longer understand how language was created [Hauser, Yang, Berwick, Tattersall, Ryan, Watumull, Chomsky, Lewontin 2014].

It turned out to be true the Second Law of Venda, which states that any factor of mutual adaptation of a person with the environment has its optimum [Venda 1982, 1990, 2017]. Creativity and

The talent of creativity and mental abilities of people, which are a factor in the mutual adaptation of people between themselves and with the external environment, were no exception.

\section{How human intellect was lowered}

There is reason to believe that evolution has reversed the intellectual development of people. Former supergenius fetuses began to lose many neurons in the womb. The total observed loss of neurons from the neocortex until the time of birth in modern Homo sapiens is about $70 \%$. 
This causes bewilderment among specialists in a subtle analysis of the dynamics of brain anatomy [Rabinowicz, Courten-Myers, Petetot, Xi, Reyes 1996; Badsberg-Samuelsen, Bonde-Larsen, Bogdanovic, Laursen, Gram, Larsen, Pakkenberg 2003]. Our study is partly a response to their request to try to find a psychological hypothetical explanation for this phenomenon.

There is data on the dependence of human mental abilities on the size and speed of neurons [Goriounova, Heyer, Wilbers, Verhoog, Giugliano, Verbist -web 2018]. If we consider that neocortex neurons are much larger than cortex neurons and thousands of times faster than the latter, then it becomes more clear the possibility of differences in the mental abilities of ancient people with a complete set of neurons in the neocortex and modern people with the number of neurons in the neocortex reduced by $70 \%$. Works on modeling the properties of neurons [Carnevale, Hines 2006] and neural networks are very promising, which may someday allow one to determine the origin of the language by filling the lack of neurons in the neocortex of modern man by modeling creative processes on future, more powerful supercomputers.

People have lost a huge part of their creative talent, ability to create a language, ceased to be supergeniuses first of grammar, then of new languages. Possibly the most tragic coincidence occurred in evolution. Homo sapiens became masters of the planet and at the same time, they lost ability to predict remote consequences of their influence on environment and on their own life.

However they gained and retain the ability to stabilize the language, to have access to natural resources, to reach accurate mutual adaptation between themselves to work, listen to music, watch sport and fight, which I called synchronization [Venda 1990].

The remaining 30\% of neocortex neurons [Badsberg-Samuelsen, Bonde-Larsen, Bogdanovic, Laursen, Gram, Larsen, Pakkenberg 2003] is enough for a small child aged 3-5 years old almost independently, only with occasional help from adults, to master any of 7000 existing languages or even two or three languages, moreover, authentic, as native [Gopnik, Meltzoff, Kuhl 1999; Kuhl 2004]. Recently, scientists have ceased to perceive children simply as underdeveloped people and are better aware of the important evolutionary purpose of children to change and create study and explore [Kuhl 2004]. 


\section{Development and initiation of child intellect}

What is meant by creative abilities manifests itself most clearly and fully in the very early years of a child's life. Many important achievements and discoveries of humankind became possible not despite the fact that a person remains a helpless child for a long time, but thanks to this [Gopnik, Meltzoff, Kuhl 1999].

The thing is that from the very beginning of life, a person joins in the process of mutual adaptation with the outside world, which is most important for him [Venda 1990]. And the person must intensively and impartially study the properties and laws of this world, in particular, the laws of mutual adaptation in order to successfully survive and fulfill itself in this complex new world.

At 11-13 years, during puberty, subconscious creative thinking (SCT) can be instilled in a teenager. The great mathematician A. Poincare [Poincare, Pontryagin (ed.) 1989, Poincare no / year web] described most fully the impression of his creative processes.

In our study, in particular, I rely on the data of an experiment lasting 70 years, which shows that if a person was somehow brought up with SCT during puberty, then the person's creativity may remain for the whole life [Venda, Venda, Venda 2015].

SCT can appear in a person in that important period of life under randomly developed favorable conditions. Perhaps it was probably with Napoleon at a military school, with A.S. Pushkin in Tsarskoye Selo Lyceum.

If a teenager did not have conditions to get SCT before the onset of puberty, and especially if he has undergone initiation in the education system, he will have only routine conscious thinking (RCT) for life.

Puberty is a very important stage in life. A person must assess his chances of success among people of the opposite sex, without which it is impossible to fulfill the main task of life - the continuation of the clan, and success among his fellow tribesmen in order to occupy a high position, help the tribe, and again continue the kind.

Moreover, a mother for a boy and a father for a girl, as well as favorite teachers of opposite sex are the most important authorities, advisers and samples [Venda, Venda, Venda 2015]. Having received help, support and motivation from adults and showing energy, temperament, character, a child can become a special creator, talent, as happened with A.S. Pushkin, Napoleon, T. Edison, and M.A. Sholokhov. 
We observed this in an experiment on the development of an ordinary child's mechanism of subconscious creative thinking (SCT), which, in our opinion, is the basis of creative talent.

Otherwise, without the support of loved ones, a very active motivation for creative success or a combination of other circumstances not yet known, the child is likely to undergo "initiation" and become the owner of the ordinary routine conscious thinking (RCT).

By initiation we understand not only ancient rites performed even today in tribes and secret societies, but any processes as a result of which a person is deprived of his individuality, creative abilities and becomes a number of strictly mutually adapted, uniform, united "cogs" of one "machine". Thanks to initiation, people acquire the ability to easily understand each other, to use better previous accumulated experience and knowledge, to work uniformly, harmoniously, hunt, fight, build pyramids, dams, factories.

The use of the term initiation should indicate that the mutual adaptation between people, the uniformity of their knowledge and actions has an ancient origin and played a crucial role in the evolution and survival of people. The initiation, providing mutual adaptation between people, has replaced the work of super geniuses who have achieved the highest intellectual heights by creating a language. However, after that, having received the most effective means of communication and mutual adaptation, people had to stop creativity and become united, uniform, and strong. People began to eradicate creativity as a source of diversity and cultivate initiation everywhere and always, from an ancient tribe to a modern high school. Finally the talents of creativity and manifestations of SCT became very rare.

Owners of RCT are much more common and sometimes successful. Such a person begins to solve any problem with a routine search of known rules. On the contrary, the owner of the SCT often tries to solve any problem as new, original. For example, according to the testimony of C. Clausewitz, who studied the battles of Napoleon, the commander never blindly followed and repeated examples including those taught in textbooks, successful battle plans. Before each battle, he collected all available relevant information and built a battle plan, carefully mutually adapted to specific unique conditions. Sixty consecutive times he defeated opponents who scrupulously followed the best experience of their predecessors, gained in other conditions. It was in principle impossible to quickly mutually adapt previous experience with new data about their troops, enemy forces, weather, soil conditions on the battlefield, and many other factors that Napoleon carefully studied, considered, and creatively synthesized, developing a new, original plan for victory. Then Napoleon before each battle 
fell asleep to provide the best conditions for his SCT. We strongly oppose suggestion by many researchers that Napoleon at such moments suffered an epileptic crisis.

We conducted psychological experiment more than seventy years long to prove possibility to bring up artificial talent in an ordinary child [Venda, Venda, and Venda 2015].

\section{Conclusion}

V.F. Venda discovered a system of four laws of mutual adaptation and transformations and developed the theory of mutual adaptation that allow studying the processes of human evolution, personal development and technological progress as multi-level mutual adaptation between a person, tools (machines, computers) and the environment. Previously the laws were tested and practically used in development of new, the transformation learning theory, in prediction of social and economic transitions, in studies of human-computer interaction, design of safe workstations, information gadgets and technological control systems, in development of new science much later named as usability. Here the laws and based on them theory of adaptation are being applied to phylogenesis of human intellect, language origin and evolution of human-environment mutual adaptation.

A century and a half of numerous unsuccessful attempts to unravel the origin of the language and the final recognition by leading modern scientists in 2014 that they cannot do this, we must admit as evidence that Homo sapiens, who created the language and its universal grammar (term by N. Chomsky), were superior to modern men in intellectual creative abilities. This is difficult to accept, since modern people have accumulated a lot of knowledge and achievements of civilization and modern science invariably recognizes our contemporary as the peak of the intellectual pyramid of the world. Yet our distant ancestors made the greatest invention, which universally recognized the creation of a language whose origin is not clear to our contemporaries.

It can be assumed that at the time of the creation of universal grammar and language, people had a neocortex with a complete set of neurons. There is evidence that a modern person loses up to $70 \%$ of neocortex neurons in the prenatal period before birth. In recent years, studies of the dependence of human mental abilities on the size and speed of active neurons have intensified. Now we know that neocortex neurons are much larger than cortex neurons and thousands of times faster than the latter. Then the difference in mental abilities of ancient people with a complete set of neurons in the neocortex and modern people with the number 
of active neurons in the neocortex reduced by $70 \%$ becomes obvious. The hypothesis of ours needs further thorough interdisciplinary checks. If this hypothesis is confirmed, it will become clear why N. Chomsky and others could not determine how ancient people created language and universal grammar. Confirmation would be very significant for philosophy, psychology and other branches of knowledge.

The author discovered the laws of mutual adaptation and transformation of systems, for the first time explaining many processes of evolution and progress [Venda 1988, 1989, 2017, Savelyev, Venda 1989, Venda, Venda 1995].

Wide international discussions of the laws of mutual adaptation and the transformation learning theory followed author's presentations at six international congresses in psychology and ergonomics, our invited lectures at 56 leading universities in the world, and at many seminars and workshops. The author was the only scientist invited to present plenary opening address twice at congresses of the US Society of Human Factors and Ergonomics in 1977 and $1992[43,54]$.

\section{References.}

[1] Badsberg-Samuelsen G., Bonde-Larsen K., Bogdanovic N., Laursen H., Gram N., Larsen J.F., Pakkenberg B. The Changing Number of Cells in the Human Fetal Forebrain and its Subdivisions: A Stereological Analysis // Cerebral Cortex. 2003. February. V. 13, № 2. P. $115-122$.

[2] Carnevale N.T., Hines M.L. The NEURON Book. Cambridge: Cambridge University Press. 2006.

[3] Chomsky N. Conditions on Transformations, in Anderson and Kiparsky (ed.), New York: Holt, Rinehart \& Winston, 1973, pp. 232-286.

[4] Chomsky N. Knowledge of Language: Its Nature, Origin, and Use. Greenwood Publishing Group, 1986.

[5] Chomsky N. New horizons in the study of language and mind. New York: Cambridge University Press, 2000.

[6] Deutscher G. The unfolding of language: an evolutionary tour of mankind's greatest invention. Metropolitan Books: New York, 2005. 
[7] Dicke U. and Roth G. Neuronal factors determining high intelligence. Philosophical Transactions of Royal Society. Biological Sciences. 2016 Jan 5; 371(1685): 20150180. doi: $10.1098 /$ rstb.2015.0180

[8] Gopnik A., Meltzoff A. N., Kuhl P. K. The scientist in the crib: Minds, brains, and how children learn. William Morrow \& Co: New York, 1999.

[9] Goriounova N.A., Heyer D. B., Wilbers R., Verhoog M.B., Giugliano M., Verbist C. Large and fast human pyramidal neurons associate with intelligence. eLife 2018;7:e41714 DOI: 10.7554/eLife.41714

[10] Hauser M. D., Yang C., Berwick R.C., Tattersall I., Ryan M.J., Watumull J., Chomsky N., Lewontin R.C. The mystery of language evolution // Frontier Psychology. 2014. № 5.

[11] Hoadley E. D. A Synergy of Theories on Human Information Processing in the User Interface. Human-Computer Interaction. Ablex: Greenwich, 1997.P. 3-12.

[12] Jerison H. J.. Evolution of the brain and intelligence. Amsterdam, The Netherlands: Academic Press. 1973.

[13] Klein R. The Human Career. Chicago University Press:Chicago, 2009.

[14] Kuhl P. K. Early language acquisition: Cracking the speech code // Nature Reviews Neuroscience. 2004. № 5. P. 831-843.

[15] Lectorsky V. A., Sadovsky V. N. Principles of the general systems research // Voprosy filosofii. 1960. No. 8 (in Russian).

[16] Lectorskiy V.A. Epistemology classical and non-classical. Moscow: URSS, 2001 (in Russian).

[17] Luce R. D., Edwards W. The derivation of subjective scales from just noticeable differences // Psychological Review. 1958. № 65. P. 222-237.

[18] Masin S. C. The (Weber's) law that never was. Proceedings of the twenty-fifth annual meeting of the International Society for Psychophysics. Galway: Ireland, 2009 P. 441446.

[19] Poincare A. Science and method // http://www.bimbad.ru/docs/poincare_science_et_myothode.pdf (in Russian).

[20] 1989 Poincare A. Value of science. Mathematical sciences. In: On science. Pontryagin (ed), Moscow: Nauka. 1989, P. 399-414 (in Russian).

[21] Rabinowicz T., Courten-Myers G.M., Petetot J.M., Xi G, Reyes E. Human cortex development: estimates of neuronal numbers indicate major loss late during gestation // $\mathbf{J}$ Neuropathol Exp Neurol. 1996. V. 55. № 3. P. 320 - 328. 
[22] Roth G. The long evolution of brains and minds. Dordrecht, The Netherlands: Springer, 2013.

[23] Savelyev A.Y., Venda V.F. Higher education and computerization. Moscow: Progress, 1989.

[24] Tattersall I. Masters of the Planet: The Search for Our Human Origins. Martin's Griffin New York, 2012.

[25] Vasin M. D. Professor Venda's «Waves progress» did not reach the Kremlin // Pravda 5. 1995. 19 - 26 may. No. 2 P. 2 (in Russian).

[26] Venda V. F. Display information. Ergonomic research and desing. M.: Energiya, 1969 (in Russian).

[27] Venda V. F. Engineering psychology and synthesis of information display systems. Moscow: Mashinostroenie, 1975 (in Russian).

[28] Venda V. F. The state and prospects of development of modern learning theories // Psychological journal. 1980. No. 4 (in Russian).

[29] Venda V. F. Engineering psychology and synthesis of information display systems. 2 ed. Moscow: Mashinostroenie, 1982 (in Russian).

[30] Venda V.F. In search of general laws of cognitive process dynamics. Psychological study of cognitive processes and personality. D. Kovach (Ed.) - Moscow: Nauka. 1982 (in Russian).

[31] Venda V. F. On the law of mutual adaptation of man and machine // Vestnik of the Academy of sciences of the USSR. 1985. No. 1. P. 39 - 49 (in Russian).

[32] Venda, V. F. On transformation learning theory // Behavioral Science. 1986. V. 31, № 1. P. 1-11.

[33] Venda V. F. The quadrigrams of mutual adaption as a new model of human activity // Proceedings of the X-th Congress of International Ergonomics Association // USW (ed.). IEA: Sydney, 1988.

[34] Venda V. F. The waves of progress. M.: Znanie, 1989 (in Russian).

[35] Venda V. F. Hybrid intelligence Systems. Evolution, psychology. Informatics. M.: Mashinostroenie, 1990 (in Russian).

[36] Venda, Venda 1991 - Venda V. F.,Venda Y. V. Transformation dynamics in complex systems // Journal of Washington Academy of Science. 1991. V. 81. № 4, P. 163 - 184.

[37] Venda, V. F., Venda Y. V. Introduction to the transformation dynamics: The law and theory of transformations // Advances in industrial ergonomics and safety. London: Taylor and Francis, 1992. P. 79-86. 
[38] Venda 1993 - Venda, V. F. Work efficiency vs. complexity: Introduction to ergodynamics // Journal of Washington Academy of Science. 1993. V. 83, № 1, P. 9 - 31.

[39] Venda, V. The quadrigrams of mutual adaption as a new model of human activity. In: Proceedings of the Xth Congress of International Ergonomics Association, Sydney, Australia, 1988.

[40] Venda, V. F. and Venda Y. V. Transformation dynamics in complex systems. Journal of Washington Academy of Science, 1991, Vol. 81, \#4, 163 -184.

[41] Venda, V. F. and Venda Y. V. Introduction to the transformation dynamics: The law and theory of transformations. In: Advances in industrial ergonomics and safety, London: Taylor and Francis, 1992, 79-86.

[42] Venda, V. F. Work efficiency vs. complexity: Introduction to ergodynamics. Journal of Washington Academy of Science, 1993, V. 83, \#1, 9 - 31.

[43] Venda V. F., Venda Y. V. Dynamics in ergonomics, psychology and decisions. Ablex: Norwood, 1995.

[44] Venda V. F., Venda V. Y., Venda L. A. Engineering psychology in the evaluation and design of information technology ( «usability»): the Russian priorities // Psychological journal. No. 2. 2013. P. 129 - 139 (in Russian).

[45] Venda V. F. Secret of the blitzkrieg. Narkoznami Hitler // https://www.proza.ru/2014/01/13/1941 (in Russian).

[46] Venda V.F., Venda V.Y., Venda L.A. On experience in bringing up of creative intellect. Psychological experiment of more than sixty years long// https://www.proza.ru/2015/09/27/1842 (in Russian).

[47] Venda V.F. Mutual adaptation of the peoples avoiding terror // https://www.proza.ru/2016/07/26/1004 (in Russian).

[48] Venda V. F. On the Laws of Mutual Adaptation and Transformations of the Systems // Voprosy filosofii. 2017. No.2. P. 95 - 105 (in Russian).

[49] Venda V.F. The laws of mutual adaptation and geopolitics // https://www.proza.ru/2017/07/09/1018 (in Russian). 